\title{
VALORACIÓN ECONOMICA DEL PAISAJE PARA LA GESTIÓN SOSTENIBLE DEL AREA DE PLAYA PUERTO VIEJO, MUNICIPIO GOMEZ, ESTADO NUEVA ESPARTA. VENEZUELA
}

\author{
Autoras: \\ María Augusta Berroterán \\ Magister en Gerencia Ambiental \\ Docente Gestión ambiental \\ Universidad Nacional Experimental Politécnica \\ de la Fuerza Armada Bolivariana \\ Ysleida González Marcano \\ Magister en Gerencia Educacional \\ Ministerio de Educación \\ República Bolivariana de Venezuela \\ ysleidarosalia@gmail.com
}

\section{RESUMEN}

Los elementos del sistema turístico, requieren la incorporación de la planificación del territorio con la mera intención de dejar por sentado los valores ambientales y culturales del paisaje. Con la investigación se busca, describir la composición del paisaje, precisar la calidad paisajística, determinar el valor económico aproximado y analizar el paisaje visual como servicio ambiental para la gestión sostenible de un área costera. La investigación es evaluativa y permite establecer un marco donde las comparaciones puedan ser hechas considerando los aspectos ambientales, estén o no en el mercado para su venta. La investigación ofrece a las ordenaciones territoriales datos acertados para elaborar políticas de gestión de recursos naturales menos sesgados hacia la producción y más eficientes de acuerdo con el valor real. Se resalta de los resultados, lo valioso del paisaje, hipotecado por las construcciones realizadas. Se considero que la cuenca visual tiene gran belleza natural.

Palabras clave: Paisaje, Desarrollo Sustentable, Valoración Económica, Cualidades Paisajísticas. 


\title{
ECONOMIC VALUATION OF THE LANDSCAPE FOR THE SUSTAINABLE MANAGEMENT OF THE BEACH AREA OLD PORT, MUNICIPIO DE GOMEZ, ESTADO DE NUEVA ESPARTA. VENEZUELA
}

\author{
Authors: \\ María Augusta Berroterán \\ Magister en Gerencia Ambiental \\ Docente Gestión ambiental \\ Universidad Nacional Experimental Politécnica \\ de la Fuerza Armada Bolivariana \\ Ysleida González Marcano \\ Magister en Gerencia Educacional \\ Ministerio de Educación \\ República Bolivariana de Venezuela \\ ysleidarosalia@gmail.com
}

\begin{abstract}
The elements of the tourist system need the incorporation of the planning of the territory with the mere intention of grounding the environmental and cultural values of the landscape. With the investigation it is sought to describe the composition of the landscape, to add the landscape quality, to determine the economic approximate value and to analyze the visual landscape as environmental service for the sustainable management of a coastal area. The investigation is evaluation-oriented and allows establishing a frame where the comparisons could be made considering the environmental aspects, either being or not on the market for sale. The investigation offers the territorial arrangements correct information to elaborate natural resource management policies less inclined towards production and more efficient according to the real value. From the results, landscape value and mortgaged by the constructions carried out stand out. It was considered that the visual basin has great natural beauty.
\end{abstract}

Key words: Landscape, Sustainable Development, Economic Valuation, Landscape Qualities. 


\section{INTRODUCCION}

Actualmente el interés por conservar el ambiente se está intensificando, y por otra parte las acciones antropogénicas, son reforzadas con la actitud del hombre consumista de productos, los cuales para su producción demandan del uso y transformación del ambiente. En este sentido, el reto evidente para el hombre es una búsqueda constante de mejorar cada día más, él mismo forma parte de ese proyecto en una escala mundial y globalizada aplicada a diferentes sectores y aspectos de la vida. Considerándose parte del problema y de la solución del mismo, insiste en vivir en armonía con el ambiente. Pero el interés de vivir en el confort, con los servicios básicos y disfrute de su entorno parece no coincidir con ambas posiciones.

Una visión integral de la situación conduce a la aplicación de la teoría de sistema, lo que implica una interacción de todos los elementos entre sí, reflejando su interdependencia. A objeto de lograr mejorar el método para perfeccionar los procesos de optimización de los recursos para su adecuado aprovechamiento y corregir los errores cometidos para asegurar progresos constantes que se evidencie en las actividades diarias y más comunes de los seres humanos.

Los recursos naturales y servicios ambientales tienen un valor económico formado por su valor de uso más los posibles valores de opción y de existencia. Esta investigación estará enmarcada en la registro de la distinción o valor singular de los espacios ideales para miradores, carreteras o vías de circulación con significación paisajística y su cotización en el mercado a objeto que se mantengan en el tiempo por ser de disfrute del colectivo y no un grupo privilegiado como viene pasando con la construcción de conjuntos residenciales que han favorecido la perdida de cuencas visuales estratégicas.

Ahora bien, es indudable que conjugar el desarrollo de una actividad económica como la turística con el ambiente arroja un resultado de gran trascendencia para la valoración económica y el manejo de recursos naturales de uso común. En Venezuela la tarea ha sido ardua a nivel de conservación ambiental, por lo que aún se buscan estrategias que conlleven a un desarrollo sostenible, que permitan lograr un repunte en los distintos sectores económicos sin dañar el ambiente y llevar la actividad turística al mismo nivel de importancia de otras actividades económicas del país. En Venezuela se le ha dado respaldo legal a la conservación y protección del ambiente, de acuerdo con la Constitución de la República Bolivariana de Venezuela (1999).

En el estado Nueva Esparta, el esfuerzo se centra en destacar además de las actividades económicas pesquera y comercial, la actividad turística para que converja 
con las labores tradicionales y costumbres propias de los nativos. Es indudable que, el estado dispone de la belleza escénica necesaria, pero, la deficiencia se tiene a nivel de Plan de Ordenación del Territorio que actualmente está en estudio para su modificación; así como por la contaminación visual, por construcciones en lugares inapropiados, que han afectado entre otras cosas la dinámica costera y por ende el paisaje original. Por lo tanto, una realidad ineludible es el valor del paisaje para los destinos turísticos porque su mercadeo y venta depende de la calidad de sus atractivos naturales y son una demostración de lo que se disfrutará al comprar o decidirse por un destino en particular.

Al respecto, la presente investigación se dirige a realizar una valoración económica del paisaje como servicio ambiental, considerándolo como una herramienta de Gestión Ambiental para desarrollar un Turismo Sostenible en Playa Puerto Viejo, Municipio Gómez, estado Nueva Esparta, a través de una descripción de los componentes en la formación del paisaje, estimando su calidad y determinando un valor aproximado del mismo.

Objetivo General: Valorar económicamente el paisaje como servicio ambiental para la gestión sostenible del área costera de Playa Puerto Viejo, Municipio Gómez, Estado Nueva Esparta.

\section{Objetivos Específicos}

- Describir los componentes básicos de los elementos que intervienen tanto en la composición como en la formación del paisaje.

- Definir la composición y dominancia visual para precisar la calidad paisajística como opción de uso sostenible de la cuenca visual donde se encuentra Playa Puerto Viejo.

- Analizar el paisaje visual o percibido en el área de estudio, considerándolo el elemento clave para el desarrollo sostenible de la actividad turística.

- Determinar el valor económico aproximado del paisaje del área de estudio.

\section{Justificación e Importancia}

El deterioro ambiental, especies en extinción, desarrollo de actividades económicas sin considerar daños en el ambiente, la valoración económica de los servicios ambientales en una isla con potencial turístico, resulta ser una de las principales opciones para fijar lineamientos hacia una gestión sostenible del Ambiente.

El desarrollo sostenible, se apoya en un trípode que define los objetivos de la sostenibilidad dados por: el crecimiento económico, valuado en términos de dinero; la 
equidad, medida en términos sociales y por último el uso sustentable de los Recursos Naturales, valuado por parámetros biogeofísicos, Una interacción equilibrada de estos factores desencadena una gestión de compromisos y conflictos que deberán negociarse con una relación ganar - ganar.

Para enfatizar el valor de los recursos naturales y por ende del paisaje como producto de la relación reciproca de los diferentes factores presentes en él, los sitios turísticos son su reflejo visual, para el estado Nueva Esparta como destino turístico, es la motivación de los turistas para visitarlo. Así se refleja en el material promocional del. Estado Nueva Esparta realizado por la Corporación de Turismo, Gobernación del estado y algunas Municipalidades, donde sobresale las playas y parques nacionales.

Pero la implementación de actividades económicas tiene un costo de afectación en los recursos naturales, en este estado, se dispone de belleza escénica espectacular que lo ubica como destino turístico de primer orden, pero es afectada por deficiencia; a nivel de Plan de Ordenación del Territorio, la contaminación visual, construcciones en lugares inapropiados que han desaparecido visuales estratégicas, afectando entre otras cosas la dinámica costera y por ende el paisaje original.

La gestión sostenible de la actividad turística compromete a muchos actores, por lo tanto se está consciente de encontrar defensores y detractores, y más aún cuando de por sí cada persona tiene una perspectiva distinta de como visualizar una misma situación. No obstante, y a pesar de que para muchos la valoración de servicios ambientales es subjetiva y debe responder a criterios morales más que a consideraciones de eficiencia económica, se plantea en la investigación, el evidente deterioro ambiental, que no sólo tiene un costo social, sino que éste se traduce siempre en un costo económico, sobre todo cuando el impacto negativo va de la mano de una actividad que depende en gran medida del paisaje como la turística.

Valorar ambientalmente un paisaje o un ecosistema en términos económicos permite establecer un marco donde las comparaciones de preferencias puedan ser hechas considerando todos sus aspectos ambientales, estén o no en el mercado para su venta. Esto permite dotar a las ordenaciones territoriales de una información más adecuada para elaborar políticas y directrices de gestión de recursos naturales menos sesgados hacia la producción y más eficientes de acuerdo con el valor real que la sociedad da a sus recursos ambientales. 


\section{MARCO REFERENCIAL}

Las valoraciones económicas como herramienta de investigación es más usada en Europa, donde al respecto vale mencionar que se cuenta con un respaldo legal bastante consolidado, como referencias se tiene la valoración económica de los humedales de Barbier, Acreman y Knowler (1997), estableciendo como modelo el método de valoración monetaria a través de Técnicas de Valoración de Humedales, también reconocida por Técnicas de Valoración Total, es decir aplicable a diferentes recursos Naturales.

En América es Costa Rica quien fija la pauta, donde se tiene una guía metodología Proyecto para la consolidación del Corredor Biológico Mesoamericano realizada por Cardenal (2002:60) seguido por Argentina, y es con la Metodología de Valoración Contingente (MCV) y la Disposición a Pagar por el uso o simple existencia de los recursos, que se destacan sin restar importancia a otros métodos según, Herman, Herrador y González (1995). En Cuba, se realizo una Aplicación de Análisis DAFO Cuantitativo Contrastables a la Playa de Guanabo (Cuba), dentro de una Gestión Costera. Correspondiente a la Facultad de Geografía de la Universidad de La Habana, 2000.

En el estado Nueva Esparta se tienen la Valoración Económica del Proceso de Descontaminación en la Laguna de los Mártires de Sánchez (2002), en este estudio se planteó estimar la Máxima Disponibilidad a Pagar (MDAP) por mejorar los niveles actuales de servicios no mercadeables, como la calidad del entorno de la Laguna, a través de un proyecto de recuperación ambiental. La cifra que resulto constituye sólo un indicador del valor que representa, en promedio, la recuperación del entorno de la Laguna para la muestra estudiada. Hidalgo (2003) realizo el estudio de la Valoración Económica de mejoras en la Calidad Ambiental. Caso: Contaminación Marina Porlamar y Pampatar, Isla de Margarita, cuyo objetivo fue valorar en términos económicos los beneficios para el desarrollo económico del estado Nueva Esparta derivados del mejoramiento de calidad de aguas. Se utilizó el método de valoración contingente, la encuesta fue el instrumento utilizado, se elaboró un modelo econométrico, arrojando como resultado una estimación del valor que representa en promedio la recuperación de la calidad fisco-química y bacteriológica del área en estudio.

El estudio más reciente es la Metodología de Valoración Integral de los Servicios Ambientales que prestan los Parques Nacionales y Monumentos Naturales, realizada por Buitrago, (2007) aquí se muestran los resultados de una metodología de valoración integral que considera los valores económicos, sociales, culturales y ecológicos de los servicios ambientales que presta los parques nacionales y monumentos naturales. Los resultados son estimaciones de su valor que resalta su importancia de preservarlos por los aportes que generan y sugiere el uso y aplicación de la planificación y gestión de desarrollo sostenible. 


\section{Bases Teóricas \\ Desarrollo Sustentable y Turismo}

El desarrollo sustentable es la opción, apoyado en los tres pilares de la sostenibilidad, ese trípode prometedor y convincente, que ofrece perfeccionamiento en las actividades económicas partiendo del hecho que mantengan una equidad social, eficiencia económica y sostenibilidad ambiental. La Comisión Mundial de Ambiente y Desarrollo, 1987 lo define como: "aquel desarrollo que satisface las necesidades del presente sin comprometer la habilidad de las futuras generaciones para satisfacer sus propias necesidades ". Se muestra como la gran oportunidad, de conservación y protección por tener el objeto de superar problemas de crecimiento de la población, contaminación, concentración urbana y rechazo a las creencias tradicionales, entre otros. Es la manera de amoldar o adaptar el desarrollo dentro del ambiente, hasta ahora bastante deteriorado.

En caso de la actividad turística, ésta deberá realizarse en forma sostenible como único camino viable, porque el lugar donde se desarrollará la actividad es siempre relacionado con un entorno natural y en su mayoría el atractivo más relevante para mercadear es la naturaleza, la cultura y las tradiciones de un lugar en particular; lo que indica cuan determinante es para la selección de un destino. Se está refiriendo entonces, al escenario donde se ejecuta la actividad que deberá cumplir con unas características particulares para poder conservarlo en el tiempo y permanecer como la atracción principal de ese destino.

La Organización Mundial de Turismo, en la Agenda para Planificadores Locales, en la edición para América Latina y El Caribe (1999) sostiene:”una iniciativa turística será sostenible, si permite mantener los valores naturales y culturales sobre los que se basa el equilibrio de la comunidad" (P.17). Esta premisa, exige una armonía entre los elementos del sistema turístico y requiere la incorporación de la planificación física del territorio con la mera intensión de dejar por sentado los valores ambientales, culturales y del paisaje. Es donde la ordenación del territorio fija la pauta para la gestión turística, según la Agenda antes citada, fija unos objetivos y contenidos de la ordenación, los cuales son: "(1) el desarrollo equilibrado y sostenible de regiones y localidades; (2) la utilización racional y responsable del territorio y de sus recursos; (3) la coordinación administrativa; (4) la mejora de la calidad de vida de los ciudadanos" (P. 51).

Existen opciones de otros instrumentos de gestión para alcanzar el desarrollo sustentable, publicados en la UNESCO (1995), donde se plantea la necesidad de:

Aumentar el desarrollo económico de los países en desarrollo; mantener la población bien informada; aumentar la base de 
conocimiento científico (a través de iniciativas de apoyo a la investigación); ampliar los sistemas de educación a información $y$ promover programas eficientes de educación ambiental, para diseminar las recomendaciones del gobierno sobre prácticas adecuadas. (s.p.)

En apoyo a una gestión coordinada de los actores del sistema turístico, Vera (1997) denominan al turismo como un "fenómeno espacial", es decir distingue el factor territorial, como determinante en primera instancia, al momento de clasificar la actividad por ejemplo, permite identificar la práctica turística por la motivación del turista, a su vez define qué tipo de turismo es; por el desplazamiento, define los flujos turísticos y por los tipos de espacio, precisa la organización espacial, modelo de asentamiento y los recursos existentes en ese espacio (P.51). Además el espacio, propone factores de localización especial en el turismo tan precisos que según afirma Vera et. al (1997), "no es una actividad económica, sino una actividad de carácter espacial que induce o genera diversas actividades económicas" (P.60). Esta aseveración, conjuga dos corrientes el espacio como recurso y como factor de la actividad, por lo tanto es el elemento que mantiene un valor social definitivo en la decisión y percepción del turista.

Los recursos, productos o servicios turísticos, son los elementos del espacio que impresionan al turista, lo atrae y motiva a definir su decisión por un destino turístico determinado. Boullon (1990) señala que "los atractivos son la materia prima de la actividad turística" . Resulta evidente esta afirmación porque son la escenografía y la locación donde se desarrolla la actividad. Las distintas modalidades de turismo son resultado del espacio geográfico, las taxonomías de esta actividad son reflejo del progreso y de las prácticas en este sector.

De ahí, la importancia de los tipos de espacios turísticos, elemento diferenciador en oportunidades y en otras coincidentes; por lo tanto, el hecho de desarrollar disímiles acciones en un mismo espacio requiere de unas exigencias, tal como lo propone Vera et. al (1997), “... la yuxtaposición de diversos tipos de turismo en un mismo espacio determina una organización espacial, un modelo de asentamiento multigenético, complejo, formal y funcionalmente, que puede dar lugar a una estructura desarticulada y con fuertes desequilibrios y conflictos" (P. 57).

En este mismo orden de ideas según Snedaker y Getter (1984) citado por Hidalgo (2003:30), "las estructuras costeras como hoteles, centros comerciales y proyectos habitacionales, tienen el potencial de cambiar los patrones naturales de dichas costas” . Al complementar con la aseveración de ese autor donde señala que la "ausencia de planificación y un manejo racional y prudente en el proceso de desarrollo, ha producido la degradación y perdida de los mismos recursos que conforman la 
atracción del turista” . Indica que conviene tomar las medidas pertinentes, como hacer cumplir con los requerimientos establecidos en el Plan de Ordenación del Territorio del estado Nueva Esparta, y como está en estudio para modificaciones incorporar las disposiciones necesarias para contribuir a un desarrollo sustentable real, tal como lo exige la Constitución del país. Por lo tanto, una muestra del interés del hombre en discernir y comprender los distintos modelos geoturísticos, son los estudios de paisaje, la ordenación territorial, y la caracterización de componentes básicos del paisaje.

\section{Paisaje Geográfico}

La ubicación geopolítica de la isla ofrece es una entrada por el mar Caribe a un multidestino, como es Venezuela, el punto estratégico que ocupa. Es un destino básicamente de sol y playa, para el descanso y la diversión, así lo indica el Perfil del Turista Nacional 2006 de la Corporación de Turismo del Estado Nueva Esparta (CorpoTur). Además, con el tiempo se ha diversificado su oferta ofreciendo sol, playa, montaña, centros comerciales, casinos, parques temáticos, eventos culturales, de negocios, entre otros, sus costumbres, sus bondades naturales, una gastronomía muy particular y la indudable amabilidad del margariteño.

Las riquezas de los elementos más característicos del paisaje costero, se visualizan en el recorrido por la carretera desde Manzanillo detallando por el lado derecho las formaciones naturales, denominados cerro Palma Real y cerro el Cacao y la derecha el majestuoso mar Caribe. En esta ruta existen varios pueblos pesqueros hasta llegar al valle agrícola de Pedro González, donde se ubica el área de estudio, se puede realizar una vista inicial total desde el mirador natural de cerro Güime; su belleza reside en la existencia del valle que lleva de una llanura al mar; donde se pueden observar los dilatados horizontes, a plenitud casi perfecta en un ángulo de $180^{\circ}$ se rota y se observa la nobleza del mar en todo su esplendor, además de los cambios practicados por el hombre entre otras cosas.

En tal sentido, interpretar y valorar el paisaje supone una dificultad y un compromiso alto, porque cada observador se crea imágenes personales de un mismo paisaje, predominando la subjetividad. Por lo tanto se deben revisar los componentes productores del paisaje, así lo sugiere Granell (2001).

Indagar en el pasado para entender el presente y aventurar en el futuro, bucear en el seno de la dinámica espacio temporal con escalas y tiempos diferentes, es decir, llegar a captar la estructura y la dinámica del paisaje, u organización y funcionamiento como sistema descubriendo las múltiples interacciones que mantienen, dentro del espacio y a lo largo del tiempo, sus diferentes componentes abióticos, bióticos y antropogénicos. (P. 162) 
Para entender y descifrar la dinámica del paisaje natural es necesario tener en cuenta los elementos generadores del mismo, para Martínez, (1994) son: la climatología, la geodinámica, las aguas subterráneas, la biocenosis y la actividad antrópica. A continuación se presenta cada uno de estos componentes que definen el paisaje. El clima depende de los procesos meteorológicos y ciclos de manchas solares. De ahí que la Climatología condiciona las cualidades del paisaje y ofrece peculiaridades en cuanto a: contenidos de la biocenosis, procesos de cambios de suelos, como base vegetal y el área geográfica para el auge de la fauna, aparte de modelar los procesos geoclimáticos externos del biotopo. La variedad de climas existentes refleja la diversidad de paisaje en el estado Nueva Esparta.

En el paisaje geográfico, vale la pena incorporar los valores complementarios a un turismo de "sol y playa", denominado así por Martínez y Casas (2002), donde se resalta en los contenidos del banco de tendencias de entorno y de contorno, en relación con el desarrollo turístico de las playas, se pueden detectar, con más frecuencia lo siguiente: Despreocupación de que las construcciones habitacionales, u otras, sean, o no, armónicas, respecto al paisaje litoral y desconocimiento de la arquitectura local, o regional, a la hora de proyectar y de ejecutar proyectos (de desarrollo o no). Se podría "contaminar", o aniquilar un paisaje peculiar y/o significativo, que se podría comportar como recurso recreacional y de esparcimiento (P. 40). Dentro de los usos turísticos o de recreación, se tiene el aprovechamiento del paisaje, desde las cuencas visuales, los puntos singulares de observación denominados como miradores y las carreteras o recorridos habituales como elementos de apreciación y estimación del paisaje, no son más que los caminos reales. Según la propuesta metodológica de Martínez (1994) se jerarquiza de la siguiente manera, las categorías paisajísticas:

- Provincias

- Sistemas de Paisajes

- Área Paisajística

- Unidad de paisaje o Cuenca visual

Donde se define la unidad, como la cuenca paisajística diferenciada, desde puntos singulares de observación; áreas paisajísticas, el conjunto de cuencas visuales identificadas en diferentes direcciones desde miradores; sistema de paisajes, al conjunto de áreas paisajísticas, dentro de un mismo dominio altitudinales; las provincias abarca el conjunto de sistemas de paisajes dentro de un mismo dominio altitudinales.

\section{El Paisaje su valor y calidad}

El territorio o espacio donde se desarrolla la actividad turística no es más que el 
paisaje, definido por Figueroa (1995), como "las unidades espaciales en que se concreta en la observación de un hecho geográfico localizable que se repite en la superficie terrestre. Entre ellos, se puede mencionar: paisaje llanero, andino..., así como también paisaje urbano, paisaje rural" (s/p). Los paisajes, son una de las más reconocidas utilidades que la naturaleza le brinda a la humanidad, por lo tanto es un servicio ambiental. Cuando este paisaje está enmarcado a un entorno natural se relaciona con la ecología. En la búsqueda de herramientas para estudiarlo, surge la Ecología del Paisaje, por su interpretación de imágenes aéreas al describir el paisaje geográfico y los componentes ecológicos.

Al respecto, existen básicamente dos tendencias, conforme a Monedero (2005), una ligada con "el estudio de un área pequeña al nivel de manchas, donde el paisaje es considerado como un mosaico de manchas dentro de una matriz, que están diferenciados por una estructura biótica y abiótica, pudiéndose describir el paisaje a partir de las especies que lo componen y el tamaño, forma, número y configuración de las manchas" (s.p.). Otra tendencia son los estudios de "el paisaje como un todo y que cubren una gran extensión de tierra en kilómetros, heterogénea, y sus elementos a considerar son: vegetación, suelo, clima y forma del relieve” (s.p.).

Se busca estimar la calidad ambiental de un área geográfica y se resalta la importancia del uso de un Sistema de Gestión de Calidad Ambiental que implica el uso o aplicaciones de trámites y formalidades pertinentes, para los usufructuarios del paisaje. Existen unos indicios que definen el grado de degradación o afectación de los recursos o servicios ambientales que se deben consideran o sirven de señal por un cambio positivo o negativo en el ambiente. Estos son los denominados, indicadores ambientales que en forma directa o indirecta miden la calidad del ambiente, pueden ser utilizados para comprobar la situación actual y las tendencias en la capacidad del ambiente para sustentar la salud ecológica y humana.

\section{Valoración económica del Paisaje}

La valoración económica del ambiente, es una herramienta de investigación que busca proteger las áreas ambientales para el bien común, restringiendo, en el buen sentido de las palabras, el desarrollo en resguardo de los recursos que esta abarca, en pro de la conservación del ambiente; y de realizarse un progreso que contemple planes de manejo de los recursos y servicios ambientales.

Valorar económicamente los recursos naturales representa poder contar con un indicador de suma importancia en el bienestar de la sociedad, que permita compararlo con otros componentes del mismo. Para ello se debe utilizar un denominador común que ayude a calcular unas cosas de otras y que, en general, no es más que el dinero. Toda valoración lleva inmersa un fin adicional a la estimación de una simple asignación del valor. Según Castelli y Spalaso (2007). 
Existen distintos tipos de valor económico que pueden agruparse en dos categorías generales: Valor de Uso: a) El valor de uso de consumo, se verifica cuando el recurso es consumido a través de su uso de modo que otras personas o actividades económicas no tengan la oportunidad de disfrutarlo. b) valor de uso de no consumo supone, en cambio, que los usuarios no consumen el recurso en el proceso de su disfrute.

El Valor de No Uso, ofrece tres perspectivas el Valor de existencia, que involucra a las personas que no utilizan el recurso, ni consideran hacerlo en el futuro, pero valoran categóricamente el estricto hecho de que exista. El Valor de no uso de legado constituye, el valor que los individuos consiguen del resguardo de características deseables del ambiente natural para las futuras generaciones. Y el último punto de vista es el Valor de opción, supone la decisión de no utilizar un recurso en el presente manteniendo la opción de utilizarlo en el futuro, es de una hipótesis temporal.

El valor económico total (VET), propuesto por Barbier, Acreman y Knowler (1997), establece que un recurso está compuesto del valor de uso (VU), y el valor de no uso (VNU). Los valores de uso se dividen a su vez, en valor de uso directo (VUD), valor de uso indirecto (VUI) y el valor de opción (VO). Además, una categoría importante del valor de no uso es el valor de existencia (VE). Se escribe entonces: VET= VU + VNU.

\section{Sustentación Legal}

Para el desarrollo de toda actividad económica se requiere del cumplimiento de una serie de permisos, requisitos o autorizaciones, de distintas índole imprescindibles para iniciar operaciones, la actividad turística no escapa de esta realidad; adicional a esto, lo concerniente al ambiente corresponde a una realidad muy particular, de hecho ha adquirido desde los años 70 un incremento persistente, con el fin de conservarlo y protegerlo, a pesar del uso indiscriminado que realiza el hombre. El paisaje como servicio ambiental y recurso del turismo constituye un valor agregado que salvaguardar, al respecto se presenta el marco legal que ampara al ambiente, para un aprovechamiento beneficioso o para el desarrollo de actividades económicas de manera responsable.

La tendencia mundial, es que los postulados constitucionales exigen que la normativa en esta materia responda a políticas ambientales internacionales, todo ello con el objeto de garantizar un desarrollo ecológico, social y económicamente sostenible, en que el uso de los recursos por parte de las presentes generaciones no comprometa el patrimonio de las futuras. En este contexto, pueden evidenciarse Constitución de la República Bolivariana de Venezuela (1999), que incorpora en forma expresa en el Capitulo IX. De los Derechos Ambientales, tres artículos relativos al manejo, conservación y protección del ambiente. Y la necesidad expresa de la Ordenación del Territorio para atender a necesidades previstas para un desarrollo sustentable o sostenible. Además, 
es importante resaltar el interés del Estado, en solicitar que toda actividad que sea susceptible a dañar los ecosistemas deberá estar acompañada de estudios de impacto ambiental (EIA).

Además en el Capítulo IV, Articulo 178, se le otorga las competencias al Poder Público Municipal, dentro de las cuales cabe resaltar las concernientes al Ambiente. En que se citan a continuación: numerales 1. "Ordenación Territorial y Urbanística....." Numeral 4. "Protección del Ambiente y cooperación con el saneamiento ambiental; aseo urbano y domiciliario, comprendidos los servicios de limpieza..." y el Numeral 6. Servicio de Agua Potable, electricidad y gas domestico, alcantarillado, canalización y disposición de aguas servidas.

Postulados que coinciden con la Ley Orgánica del Poder Público Municipal, en el Titulo III. De la Competencia de los Municipios, en el Artículo 56, en los literales $\mathrm{a}, \mathrm{d}$ y $\mathrm{f}$ donde tratan las competencias relacionadas con el ambiente. Con el objeto de procurar y garantizar en la gestión ambiental Municipal, la calidad de vida y el bienestar de las personas pobladores del Municipio. Además, es atribución de la Alcaldía crear el instrumento legal, Ordenanza municipal que norme el quehacer ambiental en su jurisdicción.

Según Troconis (2005) ésta viene a ser el complemento de la gestión del Órgano Administrativo local. También esta misma ley en el Artículo 61, señala "Cada Municipio, según sus peculiaridades, tendrá un plan local de desarrollo urbano mediante el cual se regulará el uso y aprovechamiento del suelo según las directrices contenidas en el plan nacional de ordenación urbanística...”. Es claro y contundente que le corresponde al municipio, en el Artículo 64, indica que:"A los municipios les corresponde la protección del medio ambiente..." En este caso en el Municipio Gómez se creó la Oficina Municipal de Ambiente (OMA), como la dependencia que gerencia y cumple con las atribuciones que le confieren las leyes a la unidad política primaria dentro del sistema de organización político-territorial del país.

Así mismo, la Ley Orgánica de los Espacios Acuáticos e Insulares, en su contenido precisa cómo se deben administrar estos espacios, crea el Instituto Nacional de Espacios Acuáticos (INEA), establece sus competencias, crea un fondo de desarrollo de estos espacios y sobre todo define claramente los espacios, como son altamar, plataforma continental y otras actividades conexas. En la siguiente cita se enfatiza una de las obligaciones del Estado, profundamente relacionada con el tema y el área de estudio.

La Ley de Zonas Costeras tiene por objeto "establecer las disposiciones que regirán la administración, uso y manejo de las Zonas Costeras, a objeto de su conservación y aprovechamiento sustentable, como parte integrante del espacio geográfico venezolano". 
Es preciso el tipo de desarrollo permitido en estas franjas costeras, deberá ser sostenible, con el fin de su conservación. Esta misma ley se declara en el Artículo $8^{\circ}, \ldots . "$ de utilidad pública e interés social la conservación y aprovechamiento sustentable de las zonas costeras". Ratificando la consideración anterior, corresponde entonces, establecer las variables y mecanismos de desarrollo respetando al ambiente. Y se apoya para su aplicación la Ley Orgánica de Ordenación de Territorio y la Ley Orgánica de Ordenación Urbanística. Esta última tiene por objeto "la ordenación del desarrollo urbanístico en todo el territorio nacional con el fin de procurar el crecimiento armónico de los centros poblados". Es importante resaltar que manifiesta un interés por "salvaguarda los recursos ambientales y la calidad de vida en los centros urbanos".

Una ley interesante y categórica en su contenido es la Ley Orgánica para la Ordenación del Territorio, en sus artículos expresa lineamientos de desarrollo económico y social del país, respetando el ambiente. Una demostración es el Artículo 3, Numeral 9. "La protección del ambiente, y la conservación y racional aprovechamiento de las aguas, los suelos, el subsuelo, los recursos forestales y demás recursos naturales renovables y no renovables en función de la ordenación del territorio;" Esta misma ley, le confiere atribuciones de inspección y control en los Planes de Ordenación Urbanística, así se muestra a continuación. Artículo 47.- "El control de la ejecución de los planes de ordenación urbanística, con las facultades previstas en la legislación nacional especial y las establecidas en las Ordenanzas Municipales, corresponde a los respectivos Municipios y demás entidades locales”.

En cuanto al Derecho Administrativo en materia Ambiental, es responsabilidad del Ministerio del Poder Popular para el Ambiente (MPPA), que tiene como misión, "Garantizar una mejor calidad de vida, mediante una gestión ambiental transversal, rectora, ejecutora y normativa, del uso y conservación de los recursos naturales promoviendo la participación de la sociedad para lograr el desarrollo sostenible”. Es a través de este ente que el Estado cumple con la actividad administrativa ambiental y sintetiza sus acciones en siete amplios lineamientos, que según Troconis (2005) son: “1) organización administrativa; 2) ordenación del territorio; 3) regulación de zonas especiales; 4) aprovechamiento de recursos naturales; 5) control de actividades de impacto ambiental; 6) participación ciudadana y 7) policía administrativa".

Para dar cumplimiento a la función Punitiva, se tiene la Ley Penal del Ambiente (1992), que tiene por objeto "tipificar como delitos aquellos hechos que violen las disposiciones relativas a la conservación, defensa y mejoramiento del ambiente, y establece las sanciones penales correspondientes. Así mismo, determina las medidas precautelativas, de restitución y de reparación a que haya lugar”. Así mismo se establecen las vías de penalización con las que cuenta el Estado para cumplir con su misión. En relación al procedimiento autorizatorio, es relevante indicar que este mecanismo establece 
una gestión administrativa preventiva con el fin de evitar daños, independientemente a la actividad que se desarrolle, se proyectará de manera sostenible.

Para aquellas actividades que demanden espacio o territorio, se distinguen cuatros elementos condicionantes son: "a) Ocupación del Territorio; b) Estudios de Impacto Ambiental c) Aprovechamiento de los Recursos Naturales; d) Control de Actividades Susceptibles de Degradar al Ambiente", Troconis (2005). Cada elemento es sustentado legalmente, el primero por la Ley Orgánica para la Ordenación del Territorio; el segundo, se define en las Normas sobre Evaluación Ambiental de Actividades Susceptibles a Degradar al Ambiente, definido en el Articulo 3, Numeral 1 como :

Estudio de Impacto Ambiental: Estudio orientado a predecir y evaluar los efectos del desarrollo de una actividad sobre los componentes del ambiente natural y social y proponer las correspondientes medidas preventivas, mitigantes y correctivas, a los fines de verificar el cumplimiento de las disposiciones ambientales contenidas en la normativa legal vigente en el país y determinar los parámetros ambientales que conforme a la misma deban establecerse para cada programa o proyecto.

El tercer elemento, se regula a través de la Ley Orgánica del Ambiente (2006), como es el caso del Artículo 3 A los efectos de esta Ley, la conservación, defensa y mejoramiento del ambiente comprenderá: La ordenación territorial en función de los valores del ambiente; El aprovechamiento racional de los suelos, aguas, flora, fauna, fuentes energéticas y demás recursos naturales, continentales y marinos, en función de los valores del ambiente. La creación, protección, conservación y mejoramiento de parques nacionales, reservas forestales,.... El último elemento condicionante, se apoya en Capitulo V, de la Ley Orgánica del Ambiente donde se listan supuestos y circunstancias posibles de degradar el ambiente. Para la investigación es relevante este procedimiento de autorización, porque en el área de estudio se desarrolla la actividad turística, la cual para su puesta en marcha debió cumplir con una serie de requisitos para que autorizaran a realizar los cambios ejecutados en esa zona costera.

Las referencias legales en el Sector turismo, establecidas en la Ley Orgánica de Turismo (2005) son las siguientes: en el Título I: Disposiciones Fundamentales, en su Artículo 1, señala que "tiene por objeto promover y regular la actividad turística como factor de desarrollo sustentable del país, mediante el establecimiento de normas que garanticen la orientación, facilitación, el fomento, la coordinación y el control de la actividad turística,...” (s.p.).

Así mismo, al incorporar en el artículo 2, la belleza escénica del territorio nacional, se puede ver como el paisaje o el escenario de desarrollo de la actividad turística se incorpora en la legislación vigente, por lo tanto: Quedan sometidas a las disposiciones 
de esta Ley, las actividades de los sectores público, mixto y privado, dirigidas al fomento o explotación económica lícita de índole Turístico Recreacional, en aquellos lugares o zonas del territorio nacional que por su belleza escénica, valor histórico o cultural, tengan significación turística y recreativa.

También incorpora dentro de Sistema turístico Nacional, el patrimonio natural en el Artículo 6, numeral 6. Indicando que "Se garantizará el derecho de preferencia a los pueblos y comunidades indígenas para el aprovechamiento turístico y recreacional de los paisajes contenidos en su hábitat y tierras colectivas” (s.p.). Esta Ley, le asigna a en el Título II: a los Órganos y Entes de la Administración Central y Descentralizada encargados del Turismo Capítulo I: Órgano Rector en Materia de Turismo, Articulo 8, numeral 10, la facultad de: Elaborar y mantener actualizado, conjuntamente con las autoridades de los estados y municipios y con el resto de los integrantes del Sistema Turístico Nacional, el inventario de atractivos turísticos y prestadores de servicios turísticos a través del Catálogo Turístico Nacional (s.p.).

Esta potestad se le delega a Estados y a Municipios, la cual podrán desarrollar de manera coordinada. En este mismo, Titulo II, Artículo 12. Se le asigna al ente Nacional, "Determinar las regiones dotadas de belleza escénica, o valor histórico o cultural, en consulta con las autoridades de los estados y los municipios, a los fines previstos en el artículo 2 de esta Ley”(s.p.). De esta manera, se puede observar la importancia y el valor hedónico del paisaje en general.

El Desarrollo Sustentable del Turismo, está sustentado en el Título V: Planificación de la Actividad Turística Capítulo II, Artículo 44, que señala: El desarrollo de la actividad turística debe realizarse en resguardo del medio ambiente. Las autoridades públicas nacionales, de los estados y de los municipios favorecerán e incentivarán el desarrollo turístico de bajo impacto sobre el medio ambiente, con la finalidad de preservar los recursos (s.p.). En este Título V, Capítulo III: se incorpora lo relacionado a las Zonas de Interés Turístico, Convocación Turística y Zonas Geográficas Turísticas, íntimamente relacionadas e involucradas con el aspecto espacial donde se emplaza y desenvuelve la actividad turística, tema central de la investigación. Por último, en el Título VIII, Capítulo II, Los prestadores de servicios turísticos, turistas o usuarios turísticos, Artículo 76, tienen el deber de: "1.Conservar el medio ambiente y cumplir con la normativa referente a su protección". Y en Artículo 77, resalta y considera a: "La imagen de la República Bolivariana de Venezuela y la de cada uno de sus destinos turísticos, se considera un bien colectivo protegido por la ley y nadie podrá apropiársela, perjudicarla o dañarla como consecuencia de actividades turísticas”. 


\section{MARCO METODOLOGICO}

\section{Tipo y Nivel de Investigación}

La presente investigación es evaluativa, que según Rugiero (2003) significa "aplicar conocimiento científico para acumular evidencia válida y confiable a fin de precisar en qué medida determinadas actividades o acciones producen ciertos resultados o efectos previamente definidos". (s.p.) Esta investigación consiste en la valoración económica como una propuesta para ponderar, acentuándose en las cualidades de la belleza escénica del paisaje, la información se recolectará directamente en el área de estudio.

\section{Diseño de la Investigación}

Según la Universidad Nacional Abierta (1991), el diseño de Investigación es la planificación coherente y racional de las actividades tendientes a lograr la correcta selección de los métodos, técnicas y procedimientos para el muestreo, recolección y análisis de los datos en la investigación, su objeto es proporcionar un modelo de verificación que permita contrastar hechos con teoría y su forma es la de una estrategia o plan general que determine las operaciones necesarias para hacerlo, utilizando varios tipos de diseño para definir y justificar la investigación: de campo, se basan en datos primarios, obtenidos directamente de la escenario donde ocurren los hechos (P. 39).

Debido al tipo de investigación el diseño es de campo transaccional (en un tiempo determinado), multivariable, (dos variables en estudio, la actividad turística y el paisaje) debido al que el objeto de estudio está dirigido a valorar económicamente el paisaje como servicio ambiental para la gestión sostenible de la Actividad Turística del área de Playa puerto Viejo, Municipio Gómez. Además de contar con fuentes secundarias como: textos, páginas de Internet y otros documentos.

\section{Área de Estudio}

Es el área de ubicación del Hotel Hesperia Isla Margarita, Playa Puerto Viejo y la visual desde el mirador ubicado en Cerro Güime, Municipio Gómez, estado Nueva Esparta.

\section{Población}

La población está determinada por las unidades de observación: Huéspedes, Turistas, Pobladores y Trabajadores de la Playa, Funcionarios Públicos de la Oficina Municipal del Ambiente y Turismo. Todos usuarios del área costera.

\section{Técnicas e Instrumentos de Recolección de Información:}

Se utilizó la Observación Directa, lo datos recogidos y asentados en la Planilla Generalizada ajustada al protocolo arrojando resultados de observación del recurso 
para su descripción y estimación de cualidades paisajísticas. De las Estimaciones de Feno-cualidades Paisajísticas, Se parte de un inventario de componentes básicos de los elementos que intervienen tanto en la composición como en la formación del paisaje. Se parte de tres premisas: Indicadores desglosados en descriptores, la aplicación de una escala de $0.00 \mathrm{a}+10.00$ y la obtención de los resultados, también en una escala de 0.00 a +10.00 . De esta manera, asegurar idénticas cuantificaciones. El Análisis DAFO: es cuantitativa en cuanto que se llegan a resultados numéricos, tiene carácter contrastable porque se pueden comparar las mediciones obtenidas, independientemente del operador, y toma asimismo el carácter de universalista porque se pueden comparar los resultados de diferentes lugares, medidos según misma vocación de destino y/o destino de uso.

La otra técnica fue la encuesta, con los instrumentos, cuestionario y la guía de entrevista no estructurada realizada a las autoridades de la Municipalidad para saber si están conscientes de la problemática ambiental de la zona en estudio y al representante del sector hotelero para tener información del tratamiento que dan al ambiente $\mathrm{Al}$ someter el cuestionario a su capacidad de evaluación y de proporcionar observaciones similares para ser aplicado en varias ocasiones por diferentes observadores, por el método de coeficiente de correlación de Pearson, arrojo una confiabilidad de $\mathrm{R}=0,83$, para su validez se utilizo el método de juicios a expertos. Con respecto a los cálculos para la valoración económica se considero como los más viables por presentar menos limitaciones, la Disposición a Pagar y la Valoración Directa de Mercado.

\section{PRESENTACION Y ANALISIS DE RESULTADOS}

Para la presentación y análisis de los datos se hizo por la direccionalidad establecida por los objetivos de la investigación.

En relación a los componentes básicos de los elementos que intervienen tanto en la composición como en la formación del paisaje, el territorio en estudio cuenta con una serie de recursos, físicos o naturales con condiciones de vegetación, paisajísticas, geomorfológicas, edafológicas, particularidades de la zona; y otros recursos de naturaleza antrópica, por actividades agropecuarias, desarrollos turísticos, creación de carreteras y algunas construcciones urbanas que por sus cualidades positivas, han de ser objeto de vigilancia, desde la perspectiva de la aceptación de disposiciones encauzadas a garantizar el mantenimiento, conservación y protección de los recursos ambientales.

En el primero de los casos se trata de los componentes físicos del territorio, aquéllos que presentan unas características, distinciones o valores específicos que resultan básicos en la conservación de los hábitats naturales, diversidad topográfica, la arquitectura fisiográfica, aguas superficiales, cromatismo biológico y litológico presencia de flora y fauna silvestres y del resto de elementos ambientales del territorio. 
En el segundo tipo de recursos, aquéllos que provienen de las acciones humanas, ha de partirse de la historia de la zona como su acervo cultural, tradiciones, costumbres e idiosincrasia de su gente sin negar la diversidad de culturas que se han dado como resultado el significado actual, del gentilicio margariteño; como son la carpintería de ribera, cestería, pueblos pesqueros de la zona y su gastronomía típica. Se trata de aquellos elementos del pueblo heredadas que han venido funcionando como condiciones de normas tacitas y maneras de actuar. Que provienen de códigos sociales y culturales compartidos que constituyen la identidad y tradición de un pueblo, para que sean realmente auténticos. En la zona de estudio se conjugan espacios de trabajo con áreas recreacionales de las poblaciones aledañas. Inmediatamente se presentan las estimaciones cuantitativas de las cualidades paisajísticas, en esa medida se irá describiendo el territorio.

En lo que respecta a la composición y dominancia visual para precisar la calidad paisajística como opción de uso sostenible de la cuenca visual donde se encuentra Playa Puerto Viejo, se examina el recurso ambiental por sus Fortalezas, Debilidades (análisis interno) estas son particularidades o rasgos propios del paisaje. Las Oportunidades y Amenazas (análisis externo) se presentan como las intervenciones antropogénicas realizadas en el mirador y en la cuenca visual en estudio.

Las Fortalezas del paisaje para aprovechar oportunidades y enfrentar las amenazas, es un recurso ambiental que cuenta con el recurso físico ineludible y obligatorio para ser acreditado como un mirador de relevancia, es decir las dimensiones del espacio, el cromatismo, el clima, la diversidad topográfica y su espectacularidad natural, es un paisaje con vocación por que tiene sus atributos ambientales y por sus circunstancias de contorno. De una puntuación máxima de 3,79 la valoración actual alcanza un 3,49, es decir un desvío de 0,3 en la denominación de Acervo Cultural, por lo tanto es rescatable y posible realizar para alcanzar ese 0,3 de desvío a través de la consolidación de desarrollos socioeconómicos, socioculturales y/o humanitarios de la región. Donde se refuerce y difunda los valores, tradiciones y costumbres de la región, sobretodo un Estado tan rico culturalmente.

En relación a las Debilidades del paisaje que le impiden enfrentar una amenaza o aprovechar una oportunidad, la mayor desviación la alcanza en esta parte, de una puntuación máxima de 2,11 la valoración actual alcanza un 1,39 es decir, un desvío de 0,72 distribuidas en las denominaciones de Procesos por erosión, Inocuidad de la flora, Flora y fauna exótica y el Riesgo sanitario actual por el dengue. Es factible su optimización tomando las medidas pertinentes. Como la prevención e información de los riesgos, desarrollo de planes de contingencia.

De las Amenazas del paisaje ejercidas por el hombre que pueden afectar su 
capacidad y diversidad biológica. Se obtuvo una puntuación máxima o óptima de 1,19 para las amenazas existentes en el paisaje en estudio, la valoración actual alcanza un 1,042 es decir un desvío de 0,48 en la denominación Situaciones sanitarias por el hombre accesible optimizar esta medición depende netamente del comportamiento de residentes, visitantes y los organismos competentes en el mantenimiento y limpieza de lugar.

Las Oportunidades presentes como elementos o componentes del paisaje de ocio que si son aprovechados adecuadamente, pueden proporcionarle ciertas ventajas y/o beneficios. Se tiene para este recurso ambiental, que son favorables siendo optimistas y contrario de los resultados. Porque de una puntuación óptima de 2,8 la valoración actual alcanza un 1,775 es decir, el desvío más alto se alcanza aquí, con un de 1,025 distribuidas en 2 denominaciones Accesibilidad, Servicios y equipamientos, a pesar de ser pocas tienen mucho peso.

Estas son las que muestran las mejoras del hombre para el disfrute del lugar, se es optimista porque solo con perfeccionamientos o arreglos que se le pueden hacer tanto en el recorrido usual de observación, como son la defensas en la vía, donde se requiera, señalización, entre otros acondicionamientos al mirador en sí; empezando por reconocer su belleza e incorporarlo en publicaciones. Estas mejoras deberán ser en el marco de una gestión sostenible sin comprometer en recurso, es decir de bajo impacto. En la Interpretación de la Medición en conjunto, este cálculo de las calidades ambientales, de un recurso recreacional de un territorio, como es el mirador o punto singular de observación en Cerro Güime se refiere a un conjunto de análisis, los factores internos como son las fortalezas y debilidades con un nivel. Son las variables no controlables porque son intrinsicas del ambiente, solo se puede suministrar información en relación a los items afectados para minimizar los riesgos que se pudieran ocasionar a los usufructarios y controlar, será unicamente algún riesgo sanitario. En este sentido, es antagónico a la premisa organizacional de lo que me afecta y controlo, es interno al sistema, ya que en este caso se refiere a variables ambientales.

Del análisis externo de los factores, como son las oportunidades y amenazas. Son variables que impactan en el ambiente y puede estar controlado por el hombre, son las denominadas intervenciones antropicas y pueden ser positivas o negativas. Y resulta igual de opuesto a la indicación organizacional de que los elementos externos afectan pero está fuera del control de la organización, en ambiente, se refiriere al entorno; y en este caso son direccionadas por el hombre. Donde lo negativo, son las amenazas en retrospectivos o heredados por la existencia de las intervenciones antrópicas que ya ha soportado el recurso, se notan bajas pero ya está hipotecado parte del recurso con desarrollo del Campo de Golf, al degradar el terreno; el cual es un daño permanente y con una construcción de un hotel no acorde con un diseño arquitectónico, es discordante 
con el entorno. Y las debilidades, que son las se pueden mejorar mas no cambiar. La parte positiva del estudio esta descrita por las fortalezas el recurso ambiental en sí y las oportunidades son medidas correctivas o mitigantes que se implanten e impedirán las degradaciones de las fortalezas del recurso. Y mantener las fortalezas del recurso asegurara las oportunidades del mismo, en un uso adecuado, sostenido social y económicamente enel tiempo, mediante la gestion ambiental.

En cuanto al análisis del paisaje visual percibido, se considero tres opiniones, los usuarios y trabajadores de playa Puerto Viejo, el ente municipal y el establecimiento hotelero. Al respecto, se obtuvo lo siguiente, la información socioeconómica de los usuarios y trabajadores de playa Puerto Viejo entrevistados:

a) La edad promedio está entre los intervalos de 31- 40 y 40-51.

b) Existe un predominio del sexo masculino, con un $61 \%$.

c) El grado de instrucción es de 39\% Universitarios, seguido de un 37\% bachilleres.

d) De la ocupación actual, el 57\% dependientes y 39\% independiente, en cuanto a la actividad en la que trabajan, se distinguen el $35 \%$ comercio, $11 \%$ docentes y un $11 \%$ en al área administrativa, para un total de $57 \%$.

e) El número de miembros en sus familias varía de dos a más de siete,

f) El rango de ingresos mensuales en Bs $\mathrm{F}$ de los usuarios y trabajadores de playa Puerto Viejo entrevistados, sobresalen los intervalos entre 501 y 1000 y entre 1001 y 1500 ambos con un $26 \%$, representando un total de $52 \%$, seguidos por $24 \%$ que ganan más de 2500 , se infiere que esto fue influenciado los turistas entrevistados.

En cuanto a la Valoración del Bien,

a) lo definen como un atractivo Bueno en un $48 \%$ y en un 39\% Excelente. $\mathrm{Si}$ se les hace mantenimiento de áreas adyacentes y mejora servicios, como los baños, condición de la vía, seria excelente.

b) En un 63\% está dispuesto a pagar mensualmente, en 1 año para conservarlo.

c) De los dispuestos a pagar para su conservación, proponen en primera opción con un $41 \%$ que no debe ser un monto fijo sino por colaboración, y por otra parte se tiene un $35 \%$ dispuesto a pagar entre 40 a 50 Bs. F.

d) Del 37\% que no está dispuesto a pagar, los entrevistados declaran con un $88 \%$ bastante contundente que son las autoridades quienes deben hacerse cargo de la situación. 
e) Otra forma de contribuir a su conservación, en un $48 \%$ es no degradando y con la limpieza del mismo, un 30\% no contesto, es alarmante por desconocer cuál podría ser su actitud hacia los recursos naturales para su defensa y protección.

f) Se visualiza a la alcaldía como el ente más idóneo, con un $26 \%$ como ente recaudador, se deduce por la creencia que sus funcionarios están consientes de sus realidades.

g) En relación al nivel de satisfacción, si se conserva ambientalmente esta área costera es alto, es categórico con un $93 \%$.

\section{Información Representantes del Municipio}

Para los entrevistados, Promotor de Turismo y la Jefe de la Oficina de Ambiente del Municipio Gómez, al preguntar sobre la existencia de alguna problemática en el área de estudio, la primera índico que no y la segunda manifestó un sí, indicando una degradación de la laguna existente y disposición de desechos en el área de estudio. Y considera que la medida aplicar es corregir la planta de tratamiento, por lo tanto se infiere en este nivel que la planta de tratamiento no está funcionando correctamente.

Según entrevista a funcionario del Ministerio del Poder Popular para el Ambiente, del departamento de Vigilancia y Control, conocen que existe una fuga de la planta de tratamiento en determinados momentos, pero no se ha determinado exactamente, porque en ese sitio coinciden aguas de la población y de los dos hoteles adyacentes, y los niveles de coliforme en la costa no son altos. Lo cual se comprobó con los resultados de laboratorio del Ministerio, siempre salen como playas aptas. En ningún momento se dialogo del funcionamiento de la planta salinizadora, lo cual sería interesante hacerle seguimiento, considerando que sus residuos son devueltos al mar, se desconoce en qué condiciones se realiza, es decir nivel de sal. Tampoco se conversó, sobre las lagunas del hotel, se desconoce sus condiciones de salubridad, es necesario hacerle seguimiento considerando que son utilizadas por la planta de tratamiento.

En general, durante la entrevista se pudo captar que para la adoptar medidas de mejoras solicitadas por la OMT, acciones esperadas implican un gasto, que para el municipio sus recursos son limitados y presentan otras prioridades.

En cuanto a las Medidas sugeridas por la Organización Mundial de Turismo (OMT), para un Turismo Sostenible y Gestión Municipal, considerando alcancen un turismo consciente y responsable con el ambiente, la población y cultura local, se obtuvo que el Municipio es administrado con deficiencias ambientales en oportunidades no alcanza a cumplir el mínimo, y lo que procura es mantener su identidad cultural, y planificar para que el turismo beneficio a la comunidad. A pesar de que la ley le confiere, más que cualquier otras oportunidades, y según la Ley Orgánica del Poder Público 
Municipal, en Gaceta Oficial № 38.204 del 8 de junio de 2005, en su Artículo 64, señala "A los municipios les corresponde la protección del medio ambiente y de la salubridad pública, el suministro de agua y el tratamiento de las aguas residuales, así como el respeto y garantía de los derechos ambientales de los vecinos....”.

\section{Información del Director Comercial del Hotel Hesperia Isla Margarita}

El establecimiento domina y maneja todos sus servicios básicos, con respeto a aguas blancas tiene planta salinizadora, aguas negras tiene planta de tratamiento, servicio de recolección de basura el establecimiento hotelero contrata un servicio particular y el único dependiente es el servicio eléctrico y tiene planta eléctrica para cubrir emergencia. Entre otras cosas, es alarmarte, el olor a basura o desechos por la puerta de entrada de trabajadores y proveedores, se experimento los días de la búsqueda de entrevistas, si se tiene un sistema de refrigeración de desechos, no se explica su existencia. Además de las condiciones de las instalaciones, desde afuera denota presunta falta de cuido.

En relación a las Medidas sugeridas por la Organización Mundial de Turismo, para un Turismo Sostenible y Gestión Municipal, considerando alcancen un turismo consciente y responsable con el ambiente, la población y cultura local, se obtuvo lo siguiente: Es un establecimiento con una gestión ambiental satisfactoria, a pesar de esto, quedan algunas reservas, por verificar con hechos y la mayor claridad, se insiste una vez más la urgencia de realizar algunas investigaciones y hacer seguimientos, como la calidad de aguas salientes de la planta salinizadora, calidad de agua de las lagunas, medir con mayor frecuencia el nivel de calidad de aguas de la costa, existe producción de algas en la salida aguas de la laguna, supuesta laguna aireadora de la planta de tratamiento, puede ser ribazón, pero si no existen estudios donde definan ciclos de ribazón de algas por playas, limita emisión de juicios de valor.

Es necesario realizar inspecciones de las instalaciones, para verificar las condiciones de las áreas internas y las externas, una muestra podría ser las escaleras de emergencias, suele ocurrir que frente al mar se corroa más rápido el metal, se trae referencia el caso del Hotel El Concorde, hoy día una infraestructura turística abandonada que ha hipotecado esa cuenca visual, y su recuperación es realmente onerosa.

\section{CONCLUSIONES Y RECOMENDACIONES}

\section{Conclusiones}

A partir de los resultados obtenidos del análisis descriptivo presentado, se pudo derivar una aproximación desde la visual del mirador de cerro Güime y playa Puerto Viejo, Municipio Gómez, estado Nueva Esparta, considerando las características potenciales y atractivos naturales existentes en la zona. 
1. En función de los componentes básicos de los elementos que intervienen la formación del paisaje la cuenca visual: El cerro Güime ofrece una arquitectura paisajística de gran valor escénico dentro de un destino turístico. Los riesgos de peligrosidad existentes son bajos y los existentes controlables. Se requiere es de un mejor cuidado por parte del hombre.

2. Para definir la composición visual del recurso ambiental en estudio, se considero que la cuenca visual tiene gran belleza natural. Con una valoración alcanzada, actualmente de 7,697 sobre una óptima de 9,89. Esta desviación es por sus debilidades y es factible su optimización tomando las medidas pertinentes. De las amenazas, son permanentes, porque es el hombre el adversario. A su vez, está en sus manos la oportunidad de optimizar el recurso, siempre y cuando este en el marco de una gestión sostenible sin comprometer el recurso.

3. En cuanto al Análisis del Paisaje Visual Percibido: se tiene la perspectiva de los usuarios y trabajadores de playa Puerto Viejo, los funcionarios de las coordinaciones competentes del organismo municipal y el Director Comercial del establecimiento hotelero, se presenta seguidamente:

- Los usuarios y trabajadores de playa Puerto Viejo, las encuestas arrojaron información socioeconómica, como la edad promedio de entrevistados entre los intervalos de 31-51años, personas activas, con influencia del sexo masculino, con un grado de instrucción de bachilleres a Universitarios, con una ocupación actual de dependiente con grandes grupos familiares, es decir, mayor a dos. Los ingresos de estos son superiores al sueldo mínimo.

- En relación a la valoración del bien, lo más resaltante es que están dispuestos a pagar, en forma de colaboración sin establecer un monto específico, los organismos o entes locales son los responsables de su mantenimiento, y requieren de campañas de sensibilización para la conservación del recurso ambiental. Los usuarios y trabajadores consideran que de mantenerse el recurso, se darán por dispensados.

- Información del Municipio, denota ausencia de coordinación de acciones entre comunidad en general y alcaldía, como muestra la existencia de unos baños sin conexión de aguas negras, ni comunidad ni el personal del hotel, tienen conocimiento de la situación de los mismos. Es un municipio administrado con deficiencias ambientales y en oportunidades no alcanza a cumplir el mínimo, existe limitada de conciencia de sus recursos ambientales, pero se realizan las acciones de sensibilización respecto a la basura y su recolección en sitios urbanos. Las acciones propuestas por la OMT, como acciones esperadas implican un gasto, que para el municipio sus recursos son limitados y presentan otras prioridades.

- Información del Establecimiento Hotelero, para no manifestar lo contrario por 
las reservas existente, es más bien paradójica, se señala que paralelo a condición planteada por el hotel de gestión ambiental de forma satisfactoria en cuanto a todas las acciones esperadas por la OMT. Las condiciones ambientales no pueden ser comprobables efectivamente, por el contrario existen indicios, que generan dudas. Y requiere de mayor vigilancia y control.

4. El Valor del Paisaje por costo de Habitación más las vistas, más la disposición a pagar es de $81.345 .360,20 \mathrm{Bs} \mathrm{F}$ anual, parece ser un indicador razonable. Y que existen otros elementos que se pueden valorar, y manifestar desde otra perspectiva un valor, por lo tanto aumentar el valor total de ese paisaje. Pero el objeto de estos criterios económicos, es para que los responsables de la toma de decisiones generen políticas sobre el uso de los recursos ambientales. En la actualidad, es evidente que son insuficientes las consideraciones económicas para investigaciones en el área de paisajes y servicios ambientales en general.

\section{Recomendaciones}

Considerando las conclusiones como referencia y con el propósito de contribuir con la pertinencia social- ambiental en el proceso de conservación de los recursos naturales, como atractivos turísticos y patrimonio natural del estado Nueva Esparta.

1. Los gerentes del Municipio deben asumir liderazgo, no esperar por las acciones del Ministerio del Poder Popular para el Ambiente. En cuanto a:

- Hacer cumplir las políticas ambientales

- Difundir información de uso y disfrute adecuado de recursos naturales (Plan de Manejo de Zonas Costas)

- Vigilancia y control para la conservación de los recursos.

- Realizar campañas de sensibilización en la comunidad en general, no por cumplir un plan y presentar números, sino fijando estrategias para que llegue al mayor número de habitantes. No sólo escuelas, considerar la comunidad organizada y en general.

- Para llegar a manejos que lleven a fortalezas óptimas, deberán ser plasmado en el marco de un Sistema de Gestión Ambiental, acorde con las Normas Covenin ISO 14:000, mediante la realización de Auditorías Ambientales, concebidas como el primer paso para el planteamiento de objetivos, metas y acciones que procuren: la caracterización ambiental de un territorio, la planificación y los manejos sustentables.

2. Se sugiere a los responsables y participantes de las actividades económicas en el estado Nueva Esparta, tomar las medidas pertinentes y acatar con compromiso las leyes ambientales y normativas vigentes.

3. Con los problemas actuales en el estado Nueva Esparta se deben establecer medidas preventivas, correctivas, mitigantes y de ser posible compensar cualquier impacto 
adverso importante sobre el ambiente.

4. Todas las acciones de acondicionamiento, mejora, recuperación, mitigación y las construcciones, deberá estar enmarcada en un Sistema de Gestión Ambiental Estadal, respectando los lineamientos nacionales.

5. Se debería motivar el Pago de Bienes y Servicios Ambientales (BSA) y el paisaje como herramienta de gestión ambiental en pro de un desarrollo turístico sostenible. Se fundamenta la idea de la retención de ingresos desde los beneficiarios de los BSA, para efectuar la inversión en la misma protección del recurso.

6. Se debe crear un mecanismo de pago por el uso de bienes y servicios ambientales, podría ser la oportunidad de generar recursos financieros para internalizar los recursos ambientales. Con el objeto de garantizar actividades económicas productivas y sostenibles.

7. Se requiere el alto compromiso y liderazgo por parte de los organismos involucrados (Ministerio del Poder Popular Para el Ambiente y Ministerio del Poder Popular Para el Turismo), para lograr una efectiva venta de BSA, y superar una serie de etapas secuenciales hasta llegar a su estado de plena operatividad.

8. Se propone realizar investigaciones que conduzcan a estudiar el paisaje insular, análisis económico de recursos ambientales, establecer las unidades paisajísticas del estado, definir las cuencas visuales estratégicas y de mayor relevancia, definir los sitios singulares de observaciones (miradores) y los recorridos usuales de observación en el estado, tales como las vías costeras, considerando el tipo de cuenca visual. Además de definir los paisajes que se deben conservar, preservar o restaurar, entre otras.

Estas investigaciones permitirán, identificar y valorar los bienes y servicios ambientales para determinar por un lado, sus beneficios actuales y potenciales para la sociedad y por otro lado, los costos ambientales resultantes de los impactos, producto del uso de estos recursos.

9. Se propone crear el dispositivo o mecanismo legal que contemple los Bienes y Servicios Ambientales de la biodiversidad, para poder hacerlos cumplir. Asi mismo, un mecanismo administrativo donde establezca una figura legal reguladora.

10. Se propone incorporar en el Plan de Ordenación del Territorio del Estado Nueva Esparta un capitulo de paisaje; actualmente en revisión. En donde se precise y defina las unidades paisajísticas del estado, sus cuencas visuales estratégicas y de mayor relevancia, los sitios singulares de observaciones (miradores) y los recorridos usuales de observación en el estado, reconociendo el tipo de cuenca visual. Considerando que el paisaje es un 
patrimonio natural, de uso y disfrute del colectivo y no de grupos privilegiados. Esta idea se presentaría ante el Ministerio del Poder Popular para el Ambiente, que es la Secretaria Técnica de la Comisión de Ordenación del Territorio del Estado Nueva Esparta, como la inminente necesidad de realizar Investigación, Manejo y Monitoreo de los uso de bienes y servicios ambientales a objeto de crear un mecanismo de pago.

11. Sensibilizar a los funcionarios de los organismos competentes, empresas de las distintas actividades económicas que se desarrollan en el estado y a la comunidad en general a realizar trabajos coordinados en pro de la conservación del paisaje como recurso y bien que tiene un valor determinado por las actividades a desarrollar en el, por los servicios ambientales que produce y por el simple hecho de ofrecernos servicios recreacionales.

12. La OMT, plantea una propuesta metodológica para procesos de ordenación territorial, que sugiere primero un Análisis Territorial para llegar a una formulación del plan y por último una programación de actuaciones

\section{REFERENCIAS BIBLIOGRÁFICAS}

Barbier, Acreman y Knowler (1997) Valoración económica de los humedales Guía para decisores y planificadores, Oficina de la Convención de Ramsar. Suiza

Boullon, Roberto C. (1990), Los Municipios Turísticos, Editorial Trillas, México.

Buitrago, Joaquín (2007) Valoración Económica en el Parque Nacional Laguna de la Restinga, Municipio Península de Macanao, estado Nueva Esparta. Fundación La Salle.

Casteli L. y Spalaso V. (2007) Planificación y Conservación del Paisaje. AKIAN Gráfica Editora S.A. Argentina.

Constitución Bolivariana de la República de Venezuela. (1999). Gaceta Oficial de la República Bolivariana de Venezuela, 5453, marzo 3, 2000.

Comisión Mundial de Ambiente y Desarrollo (1987). [Documento en línea]. Disponible: http://www.tierraviva.org/extras/ael/0_2005 166.html [Consulta 2008, noviembre 23] 
Cardenal, L. (2002) Guía Metodológica de valoración económica de bienes, servicios e impactos ambientales. Proyecto para la Consolidación del Corredor Biológico Mesoamericano, Editor Barzev, Radoslav, Serie 4, Nicaragua.

Corporación de Turismo del estado Nueva Esparta (2006) [Revista en línea] Disponible: http://www.corpoturmargarita.gov.ve/v2/noticias/noticias.asp?PageNo=13 [Consulta 2009, enero 30]

Figueroa, R. (1995), Programa de Estudio de Educación Básica, Ministerio de Educación, Caracas Autor

Granell, $\mathbf{M}^{\mathbf{a}}$ del Carmen (2001) Mirar, ver e interpretar el paisaje: una contribución al turismo cultural de Misiones. En Turismo Cultural y Desarrollo Sostenible. Coordinador Cebrián Aurelio Universidad de Murcia. España.

Hidalgo (2003) Valoración Económica de mejoras en la calidad ambiental. Caso: Contaminación Marina Porlamar y Pampatar. Trabajo de Grado Maestría no publicado. Universidad Central de Venezuela, Caracas

Ley Orgánica del Ambiente (2006) Gaceta Oficial de la Republica Bolivariana de Venezuela, 5.833 (Extraordinario), Diciembre 22, 2006.

Ley Orgánica de los espacios Acuáticos e Insulares (DECRETO Nº 1.437) Gaceta Oficial de la República de Venezuela 37.290, Septiembre 25, 2001

Ley Orgánica del Poder Público Municipal. (2005) Gaceta Oficial de la Republica Bolivariana de Venezuela 38.204, Junio 8, 2005

Ley Orgánica del Turismo (2005) Gaceta Oficial de la Republica Bolivariana de Venezuela 38.215, Junio 23, 2005

Ley Orgánica para la Ordenación del Territorio (1983) Gaceta Oficial de la Republica Bolivariana de Venezuela 3238( Extraordinario), Agosto 11, 1983.

Ley Penal del ambiente (1992) Gaceta Oficial de la República de Venezuela 4.358 (Extraordinario), Enero 3, 1992

Ley de Zonas Costeras (2001)(. Decreto $\mathrm{N}^{\circ} 1.468$ 27), Gaceta Oficial de la Republica Bolivariana de Venezuela 37.319, Noviembre 7, 2001.

Martínez. (1994).El Paisaje Natural y Rural desde la Perspectiva de la Ordenación, Planificación y Manejo de un Territorio. 
Martínez, J. y Casas, D. (2002). Recursos Ambientales. Servicio de Publicaciones de la Universidad de Las Palmas de Gran Canaria. Las Palmas.'

Monedero C., (2005) Ecología del Paisaje. Centro de Estudios Integrales del AmbienteUniversidad Central de Venezuela. Año 11 Números 50 enero 2005. Caracas

Organización Mundial del Turismo (OMT). (1999) Guía para Administradores Locales: Desarrollo Turístico Sostenible. España.

Herman, Herrador y González (1995) Valoración y Pago por Servicios Ambientales Prisma, No 35 1999, El Salvador

Rugiero, A (2003) Antecedentes para la formulación de un proyecto de investigación evaluativa del Programa Chile Barrio, Revista de Urbanismo, N ${ }^{\circ}$, enero 2003 ISSN 0717-5051, Chile, Departamento de Urbanismo, F.A.U. de la Universidad de Chile

Sanchez, J.(2002) Valoración económica del proceso de descontaminación en la laguna de los mártires, isla de Margarita, Venezuela. Agroalim, vol.7, no.14, p.89-103. ISSN 1316-0354.

Troconis, N. (2005) Tutela Ambiental. Tratado de Ecología, Ediciones Paredes. Caracas

UNESCO (1995) Aspectos Geológicos de Protección Ambiental, [Documento en línea] Disponible: http://www.unesco.org.uy/geo/campinaspdf/campinasprimeras.pdf. [Consulta 2008, diciembre 15]

Universidad Nacional Abierta (1991). Técnicas de Documentación e Investigación II. Caracas, autor.

Vera, P, Marchena, M. y Antón, S. (1997) Análisis Territorial del Turismo. Editorial Ariel S.A. Barcelona. España

Recibido: $11 / 02 / 2010$

Aprobado:20/05/2010

Arbitrado anonimamente 